\title{
Synchronous metastatic omental melanoma and colonic adenocarcinoma: a case report
}

\author{
Constantine Halkias ${ }^{1} 2^{*}$, Jake Sloane ${ }^{1}$, Mohamed Ben-Gashir ${ }^{1}$ and Gareth Bashir ${ }^{1}$
}

\begin{abstract}
Background: Malignant melanoma is a rare malignancy of the skin with very high mortality rates. Distal metastases are common especially to other areas of the skin, subcutaneous tissues lungs or liver. There are no previously reported cases of skin melanoma metastasizing to the omentum.

Case presentation: A 62 year-old white British man with a past medical history of a malignant melanoma of the skin underwent a laparotomy for a partially obstructing sigmoid tumour. Intra-operatively, a round, smooth textured black lesion was identified on the anterior surface of the omentum; the nodule was confirmed to be a metastatic malignant melanoma with abundant brown pigment and a focal necrotic area.

Conclusion: A metastatic malignant melanoma was discovered incidentally on the omentum during a laparotomy for bowel obstruction. The significance of this is unclear but it is possible that the omentum may have played a protective role in limiting its spread systemically.
\end{abstract}

Keywords: Omentum, Metastatic, Melanoma

\section{Background}

Malignant melanoma, although not the most common malignancy of the skin (less than 5\% of skin malignancies), is responsible for over 75 per cent of skin malignancy related deaths [1]. Distant metastases are associated with a 5 -year survival of $16 \%$ [2]. Common sites for distant metastatic deposits of malignant melanomas are other areas of the skin, subcutaneous tissues, the lungs and the liver.

In this case report we present a patient with an incidental finding of a metastatic melanoma of the omentum, discovered during a laparotomy for bowel obstruction secondary to a primary colonic malignancy.

\section{Case presentation}

A 62 year old white British man presented to our hospital with three day history of left upper quadrant pain, vomiting and abdominal distension. His past medical history included a melanoma in the right side of his face near the angle of his jaw, which was excised in 2006. Physical examination revealed tenderness on the left side

\footnotetext{
* Correspondence: halkiascj@gmail.com

${ }^{1}$ North Middlesex University Hospital NHS Trust, Sterling Way, London N18 1QX, UK

${ }^{2}$ Division of Surgery and Interventional Science 9th Floor, Royal Free Hospital, University College London, Pond Street, London NW3 2QG, UK
}

of his abdomen. His white blood cell was $15.1 \times 10^{\wedge} 9 / 1$ with a significant neutrophilia of $13.1 \times 10^{\wedge} 9 / 1$. Other blood investigations were normal. The patient underwent chest and abdominal radiography prior to computer tomography of his abdomen and pelvis.

Abdominal radiography revealed distended small bowel loops consistent with large bowel obstruction with an incompetent ileocaecal valve. Computed tomography revealed a lesion in the sigmoid colon with partial obstruction and deposits in the left lung base and peritoneum that were thought to be metastatic in nature (Figure 1).

The patient was resuscitated and operated on the next day. He underwent a left hemicolectomy with a defunctioning ileostomy. Intra-operatively, a round, smooth textured black lesion was identified on the anterior surface of the omentum, measuring $30 \times 25 \times 22 \mathrm{~mm}$. It was excised along with its surrounding omentum and sent for histopathology separate to the colonic specimen (Figure 2).

The histology report stated a moderately differentiated adenocarcinoma of the left colon with two positive lymph nodes (TNM5 - pT4b, N1, Mx, R0). The omental nodule was confirmed to be a metastatic melanoma (Figure 3). 


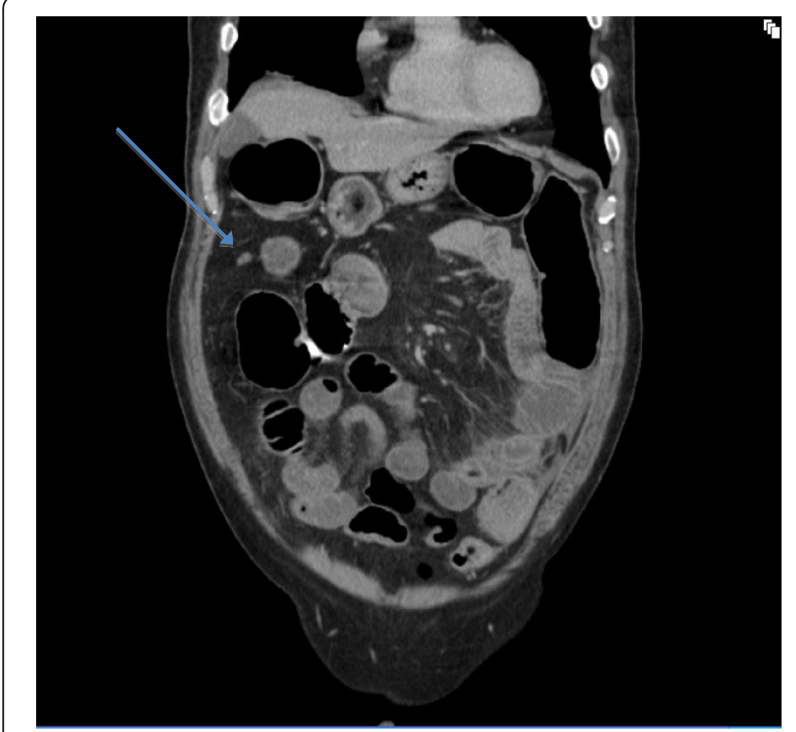

Figure 1 Coronal section of the CT scan. The blue arrow is pointing to a small round lesion in the right upper quadrant, most likely representing the omental lesion.

The metastatic melanoma was $100 \%$ clear on $\mathrm{H} \& \mathrm{E}$ sections with nested pattern and abundant brown pigment. Immunohistochemistry confirmed the diagnosis and the melanoma cells were positive for the melanocytic markers S100, MelanA and HMB45.

Post-operative physical examination did not reveal any obvious cutaneous lesions.

\section{Conclusions}

Although visceral and peritoneal metastasis of melanoma is not actually a rare condition, no previous cases of omental metastasis of cutaneous melanoma have been reported. The only similar case, published by Zhao et al. [3] is of a melanoma of choroidal origin metastasising to the omentum [3].

Melanoma is an aggressive tumour and metastatic disease has a very poor prognosis.

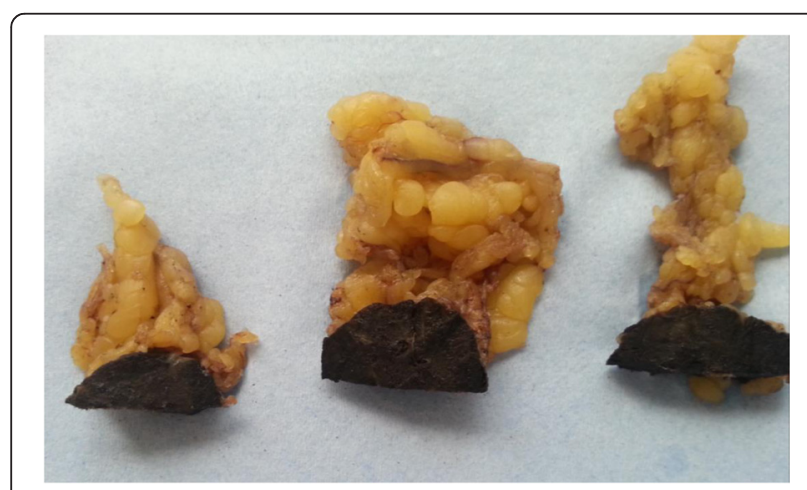

Figure 2 Macroscopic images of the specimen.

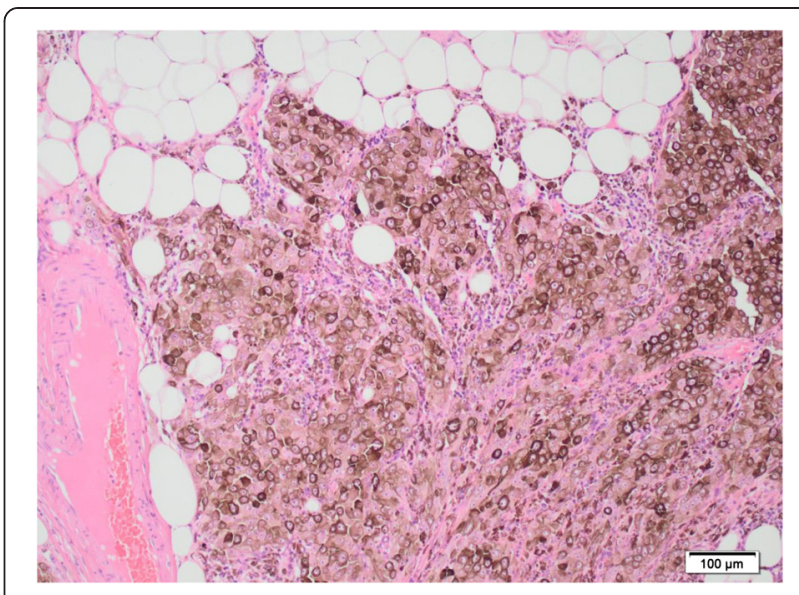

Figure 3 Microscopic image of the specimen confirming the diagnosis of an omental melanoma.

Resection is the treatment of choice in the absence of disseminated disease [4].

Current guidance [4] in distant metastatic disease, after resection, suggests either a palliative approach or inclusion in a clinical trial.

The mechanisms of metastasis are not very straightforward and a lot is yet to be understood of melanoma's metastatic behaviour.

There have been several reports of late distant metastases, even 17 [5] and 24 [6] years after the initial diagnosis, and metastases to areas which are not common sites of metastasis $[5,7,8]$. All the above, are suggestive of a tumour with a behaviour that is not always predictable. In our case it involved the omentum, an extremely rare site for metastasis.

Going through our patient history, the initial cutaneous melanoma excised from the jaw was in fact reported as metastatic in nature ("Dermal deposit of metastatic melanoma”). However, no primary tumour was ever found and hence it was treated as if it were a primary. Given the unpredictable behaviour of these types of tumours, it is difficult to estimate how long the discovered omental lesion had been present. Just as the omentum plays a protective role in isolating sepsis and inflammation in intra-abdominal disease, it is theoretically possible that the omentum may have played a role in containing the melanoma locally.

\section{Consent}

Written informed consent was obtained from the patient for publication of this Case Report and any accompanying images. A copy of the written consent is available for review by the Editor-in-Chief of this journal.

\section{Abbreviations}

TNM: Tumour, Nodes, Metastases. 


\section{Competing interests}

The authors declare that they have no competing interests. No financial support has been received.

\section{Authors' contributions}

$\mathrm{CH}$ drafted the manuscript and conducted a literature search. JS, GB and MBG conducted a literature search and contributed to drafting the manuscript. JS and GB performed the operation. MBG was the histopathologist who examined the specimens, made the final diagnosis and provided the pictures. All authors read and approved the final manuscript.

\section{Acknowledgements}

We would like to acknowledge the invaluable support of all the nurses and on call staff who take care of our patients.

Received: 25 June 2014 Accepted: 26 March 2015

Published online: 03 April 2015

\section{References}

1. Jerant $A F$, Johnson JT, Sheridan CD, Caffrey TJ. "Early detection and treatment of skin cancer". Am Fam Physician. 2000;62(2):357-68. 375-6, 381-2.

2. American Cancer Society. Cancer Facts \& Figures. American Cancer Society. 2015: [http://www.cancer.org/acs/groups/content/@editorial/documents/ document/acspc-044552.pdf]

3. Zhao H, Yang M, Zhang X, Zhao S, Yao G, Zhou D, et al. The first case of omental metastasis from primary choroidal melanoma. Jpn J Clin Oncol. 2013;43(3):314-7

4. Bishop JA, Corrie PG, Evans J, Gore ME, Hall PN, Kirkham N, et al. Cox NH; Melanoma Study Group; British Association of Dermatologists. UK Guidelines for the management of cutaneous melanoma. Br J Plast Surg. 2002;55(1):46-54.

5. Uchiyama S, Imamura N, Ohuchida J, Hiyoshi M, Nagano M, Marutsuka K, et al. Late recurrence of malignant melanoma in the duodenum. Hepatogastroenterology. 2008;55(86-87):1619-21.

6. Slattery E, O'Donoghue D. Metastatic Melanoma presenting 24 years after surgical resection: a case report and review of the literature. Cases J. 2009:2:189. doi:10.1186/1757-1626-2-189.

7. Fambrini M, Andersson KL, Buccoliero AM, Pieralli A, Livi L, Marchionni M. Late solitary metastasis of cutaneous malignant melanoma presenting as abnormal uterine bleeding. J Obstet Gynaecol Res. 2008;34(4 Pt 2):731-4. doi:10.1111/j.1447-0756.2008.00917.x.

8. Bahat G, Saka B, Colak Y, Tascioglu C, Gulluoglu M. Metastatic gastric melanoma: a challenging diagnosis. Tumori. 2010;96(3):496-7.

\section{Submit your next manuscript to BioMed Central and take full advantage of:}

- Convenient online submission

- Thorough peer review

- No space constraints or color figure charges

- Immediate publication on acceptance

- Inclusion in PubMed, CAS, Scopus and Google Scholar

- Research which is freely available for redistribution 